\title{
Movement of Walleyes in Lakes Erie and St. Clair Inferred from Tag Return and Fisheries Data
}

\author{
Hui-Yu Wang* AND Edward S. Rutherford \\ Institute for Fisheries Research, School of Natural Resources and Environment, University of Michigan, \\ Ann Arbor, Michigan 48109-1084, USA \\ H. ANDREW COOK \\ Ontario Ministry of Natural Resources, Lake Erie Fisheries Station, \\ Rural Route 2, 320 Milo Road, Wheatley, Ontario NOP 2P0, Canada \\ Donald W. Einhouse \\ New York State Department of Environmental Conservation, Lake Erie Fisheries Research Unit, \\ 178 Point Drive, North Dunkirk, New York 14048, USA
}

\author{
ROBERT C. HAAS
}

Michigan Department of Natural Resources, Mt. Clemens Fisheries Station, South River Road, Harrison Township, Michigan 48045, USA

TIMOTHY B. JoHNSON

Ontario Ministry of Natural Resources, Lake Ontario Fisheries Station, Rural Route 4, 41 Hatchery Lane, Picton, Ontario K0K 2T0, Canada

\section{ROGER KENYON}

Pennsylvania Fish and Boat Commission, Division of Research, Box 531, 2000 Lohrer Road, Fairview, Pennsylvania 16415, USA

\section{BRIAN LOCKE}

Ontario Ministry of Natural Resources, Lake Erie Fisheries Station, Rural Route 2, 320 Milo Road, Wheatley, Ontario NOP 2P0, Canada

\author{
MARK W. TURNER \\ Ohio Department of Natural Resources, Division of Wildlife, Lake Erie Headquarters, \\ 305 East Shoreline Drive, Sandusky, Ohio 44870, USA
}

\begin{abstract}
Lake Erie walleyes Sander vitreus support important fisheries and have been managed as one stock, although preliminary tag return and genetic analyses suggest the presence of multiple stocks that migrate among basins within Lake Erie and into other portions of the Great Lakes. We examined temporal and spatial movement and abundance patterns of walleye stocks in the three basins of Lake Erie and in Lake St. Clair with the use of tag return and sport and commercial catch-per-unit effort (CPUE) data from 1990 to 2001. Based on summer tag returns, western basin walleyes migrated to the central and eastern basins of Lake Erie and to Lake St. Clair and southern Lake Huron, while fish in the central and eastern basins of Lake Erie and in Lake St. Clair were primarily caught within the basins where they were tagged. Seasonal changes in sport and commercial effort and CPUE in Lake Erie confirmed the walleye movements suggested by tag return data. Walleyes tagged in the western basin but recaptured in the central or eastern basin of Lake Erie were generally larger (or older) than those recaptured in the western basin of Lake Erie or in Lake St. Clair. Within spawning stocks, female walleyes had wider ranges of movement than males and there was considerable variation in movement direction, minimum distance moved (mean distance between tagging sites and recapture locations), and mean length among individual spawning stocks. Summer temperatures in the western basin often exceeded the optimal temperature $\left(20-23^{\circ} \mathrm{C}\right)$ for growth of large walleyes, and the
\end{abstract}

\footnotetext{
* Corresponding author: hyw@umich.edu
}

Received January 15, 2006; accepted October 9, 2006

Published online March 22, 2007 
migration of western basin walleyes might represent a size-dependent response to warm summer temperatures. Cooler temperatures and abundant soft-rayed fish probably contributed to an energetically favorable foraging habitat in the central and eastern basins that attracted large walleyes during summer.

Walleyes Sander vitreus are an important sport and commercial fish in North America and one of the top predators within the Great Lakes food web. In Lake Erie and Lake St. Clair (LSC), walleyes are harvested by tribal groups, four U.S. states, and the province of Ontario, and the production of walleyes in Lake Erie is the largest in the Great Lakes (Fielder 2002). Consequently, factors affecting walleye abundance and distribution are of great concern to Lake Erie fisheries managers.

Previous research suggests that walleye abundance and distribution in Lake Erie are related to water quality, trophic structure, and the presence of invasive species (Makarewicz and Bertram 1991; Knight and Vondracek 1993; Fitzsimons et al. 1995; Koonce et al. 1996; Ludsin et al. 2001). In addition, habitat heterogeneity in Lake Erie may influence walleye spatial distribution (Nepszy 1999; Ohio Department of Natural Resources 2001). Lake Erie is comprised of three distinct basins that vary in depth, temperature, and productivity (Rasul et al. 1999; Schertzer 1999). The depth gradient results in vertically mixed, relatively warm waters in the shallow western basin (WB) and progressively stratified cooler temperatures in the deeper central basin (CB) and eastern basin (EB). The interaction of bathymetry, temperature, and food abundance in the three basins in Lake Erie may cause variation in walleye abundance and spatial distribution.

Lake Erie walleyes have been managed as a single stock, but are comprised of several genetically distinct stocks (Merker and Woodruff 1996; Stepien and Faber 1998; McParland et al. 1999; Gatt et al. 2003). Previous tagging studies suggested that walleye stocks in western Lake Erie migrate north to LSC and Lake Huron, while stocks in Lake Huron and LSC also migrate south to Lake Erie through connecting waters (Wolfert 1963; Ferguson and Derksen 1971; Haas et al. 1988; Todd and Haas 1993). More recent tag return data indicated that walleyes migrate from western Lake Erie to eastern Lake Erie during summer (Einhouse and Haas 1995). However, there has not been a quantitative assessment of walleye movement inferred from the tag return data, as fishing effort was implicitly assumed constant throughout Lake Erie and LSC.

Studies of Lake Erie walleye biology and movements have mainly focused on local stocks in the WB and CB (Knight et al. 1984; Hatch et al. 1987; Hartman and Margraf 1992; Knight and Vondracek 1993; Madenjian et al. 1996; Gopalan et al. 1998). Kershner et al. (1999) used an individual-based bioenergetics model to simulate growth and consumption rates of resident adult walleyes in the $\mathrm{WB}$ and $\mathrm{CB}$ and of a population that migrates between basins. The model predicted that (1) walleyes residing in the WB should have lower growth and consumption rates than walleyes residing in the $\mathrm{CB}$ or a population migrating between the two basins and (2) the interbasin variation in growth rate could be explained by temperature. Model results indicated that higher summer temperatures in the WB may limit adult walleye growth by raising metabolic costs, and fish that migrate between basins may take advantage of optimal temperatures for growth in either basin. Based on Kershner et al.'s (1999) prediction, WB walleyes should all migrate to the $\mathrm{CB}$ or $\mathrm{EB}$ during the summer to optimize their growth. However, the tag return data indicated that walleyes did not migrate as precisely as the model suggested. Kershner et al. (1999) made assumptions regarding walleye migration timing, age distributions, and sex ratios without information from tag returns or observed growth data, potentially biasing modeling results. Therefore, the goal of this paper is to examine walleye movement patterns with the use of recent data from all Lake Erie basins to reevaluate the model predictions of Kershner et al. (1999).

As fish movement behaviors generally represent life history strategies of a population (Mellina et al. 2005), it is important for fishery managers to identify distinct movement patterns among individual walleye stocks. In this paper, we provide an explicit quantification of walleye movement in Lake Erie by analyzing walleye tag return data, accounting for spatial and temporal changes in fishing effort. We first quantified walleye movement by calculating tag return rates standardized by lakewide sportfishing effort per Lake Erie basin. We then explored seasonal movement patterns of individual stocks and of both sexes. Finally, we examined monthly sportfishing and commercial fishing effort and catch rate data to infer seasonal changes in walleye density distributions among Lake Erie basins. Our objectives were to quantify and differentiate movement patterns of individual walleye stocks and to relate patterns in sport and commercial catch rates to walleye movement.

\section{Methods}

Study Area

Schertzer (1999) summarized the physical characteristics of Lake Erie habitats based on literature reviews, lakewide cruise surveys, and remote-sensing 


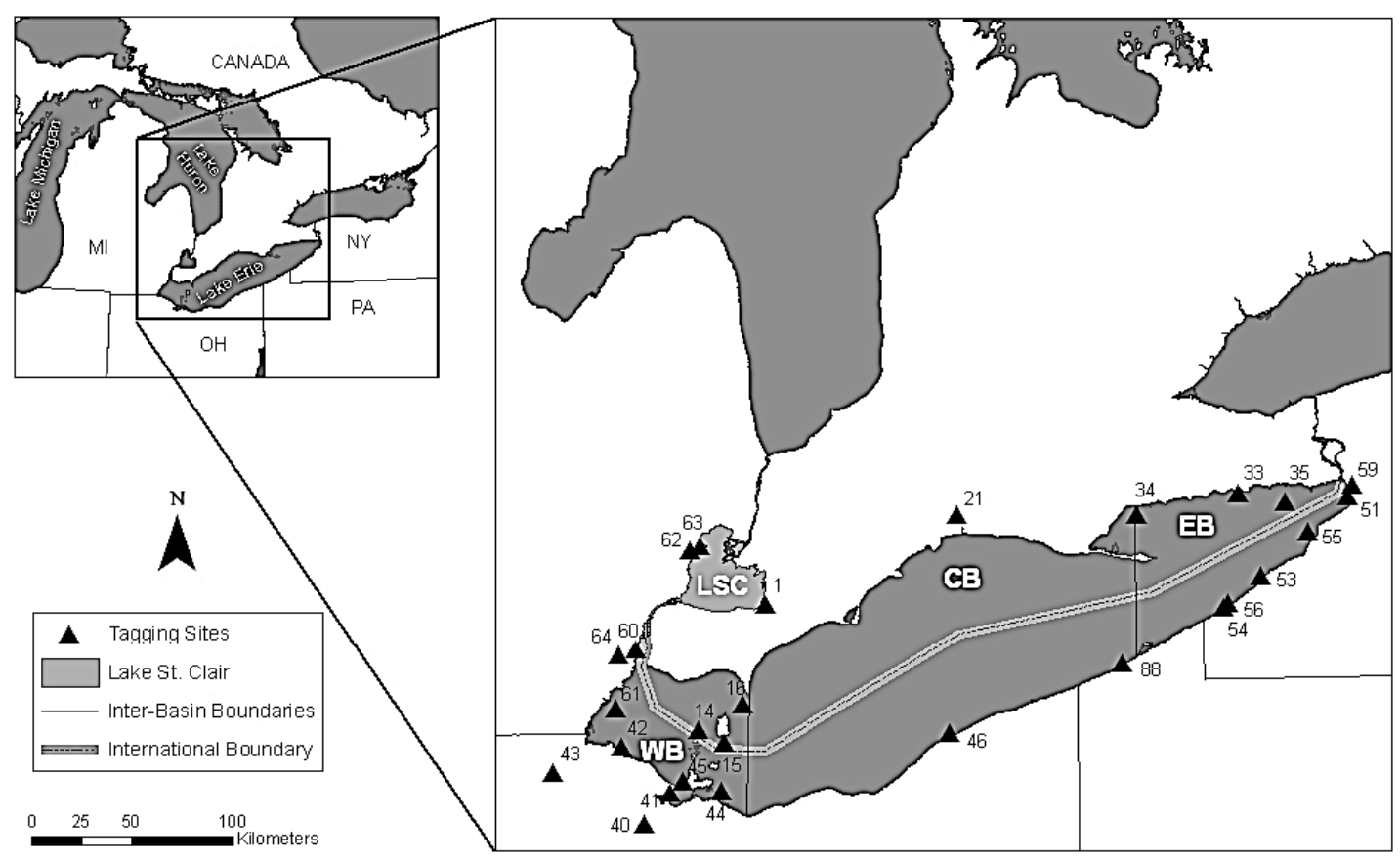

FIGURE 1.- Interbasin and international boundaries and locations of walleye tagging sites in the western (WB), central (CB), and eastern (EB) basins of Lake Erie and in Lake St. Clair (LSC), 1990-2001. See Table 1 for tag site identifications.

data. Lake Erie is the shallowest of the five Great Lakes and contains three basins: WB, CB, and EB. The WB and $\mathrm{CB}$ are separated by an island chain extending from Point Pelee south to east of Sandusky Bay in Ohio. The CB and EB are separated by the Pennsylvania Ridge, which connects Long Point, Ontario, to Erie, Pennsylvania. For analyses, we defined basin borders that approximate these natural boundaries according to Ludsin et al. (2001; Figure 1).

The bathymetry of Lake Erie forms very distinct limnological characteristics in the three basins. The $\mathrm{WB}$ is the shallowest (mean depth $=7.4 \mathrm{~m}$ ) and warmest basin; it has isothermal water temperatures from surface to bottom through the growing season. The CB has the largest surface area and a relatively flat bottom (mean depth $=18.5 \mathrm{~m}$ ). Water stratification and strong wind mixing together result in complex and unstable temperature profiles (D. Schwab, National Oceanic and Atmospheric Administration, personal communication). The EB (mean depth $=24.4 \mathrm{~m}$ ) stratifies consistently in summer and has cooler temperatures below the thermocline.

\section{Data Sources}

Tag return data (1990-2001).-Lakewide walleye tagging has been conducted in Lake Erie since 1986 by resource agencies in Michigan, Ohio, Pennsylvania,
New York, and Ontario. Fish were captured from several spawning sites (Figure 1; Table 1), jaw-tagged with monel metal tags, and released at the same sites in Lake Erie, LSC, and their tributaries during March to early May. During some years, plastic streamer tags also were used (sewn into the dorsal musculature with monofilament nylon) in Ontario waters of Lake Erie. The resource agencies used several gear types to capture walleyes, including trap nets (Michigan, New York, Ohio), seines (Ohio), gill nets (Ontario), and electroshocking (Ohio, New York). Between 1986 and 2000, 104,983 walleyes were tagged and released at 27 sites: 3 sites in LSC, and 12,3, and 9 sites in WB, CB, and EB of Lake Erie, respectively (Tables 1, 2; Figure 1). Not every site was sampled each year.

Rewards for tag returns were offered in 1990 and 2000 to assess nonreporting rates for walleye tags by commercial and sport fishermen. A reward of US\$100 was applied to $10 \%$ of the tagged walleyes at several tagging sites (Thomas and Haas 2001). The nonreporting ratios (tag return rate for reward tags divided by tag return rate for nonreward tags) during the 2 years studied were similar. Estimated nonreporting ratios for anglers (mean $=2.6$ ) were lower than those for commercial fishermen (mean $=22.4$ ). Based on this study, we considered that tag return rates by commercial fishermen might be less reliable and we excluded 
TABLE 1.-Walleye tagging sites in Lake St. Clair (LSC), three basins of Lake Erie (western [WB], central [CB], and eastern [EB]), and their tributaries during 1990-2001. Asterisks denote major walleye spawning sites.

\begin{tabular}{ccl}
\hline Basin & Tagging site & \multicolumn{1}{c}{ Description } \\
\hline LSC & $1^{*}$ & Thames River \\
& $62^{*}$ & Clinton River (near Mt. Clemens) \\
& 63 & Clinton River (near LSC) \\
WB & $14^{*}$ & Chicken and Hen Islands \\
& 15 & Chickenolee Reef \\
& 16 & Grubb Reef \\
& $40^{*}$ & Sandusky River \\
& $41^{*}$ & Sandusky Bay \\
& 42 & Bono \\
& $43^{*}$ & Maumee River \\
& 44 & Cedar Point \\
& $45^{*}$ & Sugar Rock \\
& 60 & Detroit River \\
CB & $61^{*}$ & Raisin River \\
& 64 & Huron River \\
& 21 & Port Stanley \\
EB & $46^{*}$ & Grand River \\
& 88 & Walnut Creek \\
& 33 & Port Maitland \\
& 34 & Port Dover \\
& 35 & Port Colborne \\
& $51^{*}$ & Lackawanna Shoreline \\
& $53^{*}$ & Van Buren Bay \\
& 54 & Shorehaven \\
& 55 & Evan's Bar \\
& 56 & Barcelona \\
& 59 & Buffalo River \\
\hline & & \\
& & \\
& &
\end{tabular}

tags returned by commercial fishermen from our analyses. The sport return tags $(6,376$ tags, or $82 \%$ of all returned tags) represented fish from all spawning stocks.

The proportions and sex ratios of tagged walleyes in each basin were uneven. Approximately 4.9, 79.0, 2.7, and $13.4 \%$ of all walleyes tagged were released in LSC, WB, CB, and EB, respectively (Table 2). The sex ratio of tagged walleyes was skewed toward males in all basins (Einhouse and Haas 1995), as males were more vulnerable to the sampling gear on spawning grounds.

Primary measurements of tagged walleyes included length, weight, age, sex, and maturity, as well as water temperature and Secchi depth at the tagging sites. Data on recaptured walleyes included length, weight, recapture date, and location. We used the initial tagging information of recaptured walleyes to estimate stock parameters (i.e., mean length). Movement patterns of walleyes were quantified by taking locations of tagging and recapture sites as start and end points of walleye movement paths. We excluded data collected before 1990 or after 2000 in which sample sizes were too small for analysis.

Sport and commercial effort and catch rate data (1990-2001).-Walleye effort and catch rate (catch per unit effort [CPUE]) data were estimated from creel surveys of sport fishermen in the southern part of Lake Erie (conducted by Michigan, Ohio, Pennsylvania, and New York biologists), as well as from mandatory daily catch reports of commercial fisheries in the northern part of Lake Erie (estimated by Ontario biologists). Sportfishing CPUE was defined as number of walleyes caught per fishing hour (fish/angler-hour), and data were summarized monthly in $10-\times 10$-min grid cells that covered Lake Erie. The 10- $\times 10$-min grid system is commonly used as a unit for data recording by fish biologists in the Great Lakes (e.g., Höök et al. 2004). Fishing effort data from charter boat fishermen did not include details on number of fishermen per boat and were not used in the analyses. Commercial CPUE was measured as weight of walleyes caught per unit length of gill nets $(\mathrm{kg} / \mathrm{km})$ that targeted walleyes, and data were reported monthly in 5 - $\times 5$-min grids. We used the sport and commercial CPUEs, respectively, to index walleye spatial and temporal abundance and biomass distributions. By doing so, we assumed that sport and commercial fishermen went fishing in areas where density (in abundance, biomass, or both) of walleyes was high relative to other areas in Lake Erie.

\section{Analyses}

Walleye spatial distribution and movement inferred from tag return data.-The conventional assumptions for tag return analyses (e.g., Schwarz et al. 1993) were applied in our analyses. For example, we assumed that (1) the survival and chance of being caught were equal for tagged and untagged fish, (2) the tag loss rate was $0 \%$, and (3) each tagged fish was independent of other tagged or untagged fish. In addition, we assumed that

TABLE 2.-Number of tagged walleyes released and number of tags returned annually by sport fishermen in Lake St. Clair (LSC) and the western (WB), central (CB), and eastern (EB) basins of Lake Erie during 1990-2001. Fish recaptured in the Detroit River, St. Clair River, and southern Lake Huron were grouped into LSC recaptures $(\mathrm{NA}=$ unavailable data).

\begin{tabular}{|c|c|c|c|c|c|c|c|c|}
\hline \multirow[b]{2}{*}{ Year } & \multicolumn{4}{|c|}{ Released tags } & \multicolumn{4}{|c|}{ Recovered tags } \\
\hline & LSC & WB & $\mathrm{CB}$ & EB & LSC & WB & $\mathrm{CB}$ & $\mathrm{EB}$ \\
\hline 1990 & 3,291 & 28,355 & 436 & 1,115 & 217 & 207 & 103 & 69 \\
\hline 1991 & 715 & 8,602 & 508 & 1,655 & 243 & 344 & 110 & 65 \\
\hline 1992 & 553 & 7,260 & 788 & 1,954 & 163 & 370 & 129 & 61 \\
\hline 1993 & 0 & 7,359 & 397 & 1,906 & 174 & 462 & 176 & 166 \\
\hline 1994 & 415 & 5,539 & 184 & 1,477 & 113 & 239 & 150 & 231 \\
\hline 1995 & 132 & 5,600 & 282 & 1,314 & 77 & 194 & 119 & 143 \\
\hline 1996 & 0 & 5,718 & 45 & 894 & 24 & 167 & 136 & 203 \\
\hline 1997 & 0 & 6,261 & 0 & 1,144 & 69 & 197 & 75 & 141 \\
\hline 1998 & 0 & 1,668 & 0 & 459 & 37 & 119 & 71 & 136 \\
\hline 1999 & 0 & 1,630 & 0 & 1,086 & 25 & 61 & 25 & 99 \\
\hline 2000 & 0 & 4,958 & 162 & 1,121 & 48 & 91 & 39 & 133 \\
\hline 2001 & NA & NA & NA & NA & 14 & 80 & 28 & 84 \\
\hline Total & 5,106 & 82,950 & 2,802 & 14,125 & 1,204 & 2,531 & 1,161 & 1,531 \\
\hline
\end{tabular}


the rate of tag return by sport fishermen was a function of fish movement and activities of sport fishermen based upon the positive correlation $\left(r^{2}=0.75 ; N=31\right.$; $P<0.0001)$ between total number of tags returned and sportfishing hours. Moreover, variation in behaviors and conditions of fish (e.g., tag loss, vulnerability, and survival rates) and behaviors of fishermen (e.g., willingness to return tags, preferences for certain types of walleyes, etc.) at different locations were assumed to have only random effects on tag return rates. The recapture locations of tagged walleyes were classified by basin (LSC, WB, CB, and EB; Figure 1). Tagged fish recaptured in the Detroit River north of tagging site 60; St. Clair River, Saginaw Bay, and Lake Huron were grouped as LSC recaptures to increase sample size in LSC. Standardized tag return rates per basin were calculated as number of tags returned per 1,000 tags released per year multiplied by relative total sportfishing effort (relative to effort spent in the WB in the same year). We did not have sportfishing effort data in LSC for the study time period, so we only estimated tag return rates in $\mathrm{WB}, \mathrm{CB}$, and $\mathrm{EB}$.

We used analysis of variance on standardized tag return rates (see above) to evaluate variation in proportions of fish tagged per basin that were recaptured in $\mathrm{WB}, \mathrm{CB}$, or $\mathrm{EB}$. Similarly, we compared mean length at tagging of male and female walleyes among basins. Level of significance $(\alpha)$ for the statistical tests was set at 0.05 .

The tag return data allowed us to investigate movement patterns at the resolution of the walleye spawning stock. We defined walleye spawning stocks based on where fish were tagged (Figure 1), as Lake Erie walleyes are known to home toward spawning sites. However, previous studies on genetics of Lake Erie walleyes suggested that these fish stocks might not all be genetically distinct (Stepien and Faber 1998). We selectively examined data on two LSC stocks (1 and 62; Figure 1), six WB stocks (14, 40, 41, 43, 45, and 61 ), one CB stock (46), and two EB stocks (51 and 53), which each had at least 180 tags returned by sport fishermen during the study period. We compared direction from tag site to recapture location (movement path), minimum distance moved per recapture month, and mean length of fish of both sexes of these individual stocks. Minimum distance moved per recapture month was calculated by averaging distances between tagging site and recapture locations of all recovered walleyes from one stock during each month of the sportfishing season (April-September).

Temporal and spatial patterns of sport and commercial effort and CPUE.-We calculated means and standard errors of walleye sportfishing and commercial fishing effort and CPUE data from the period 1990-
2001 by month and basin. Walleye movement across Lake Erie basins was inferred from seasonal changes in effort and CPUE.

\section{Results}

Walleye Tag Return Rates and Length at Tagging among Lake Erie Basins

Composition of tag returns among basins varied over time (Table 3). Standardized tag return rates showed that fish tagged in one basin had a higher chance of being caught in the same basin (Table 3 ). The fish tagged in LSC had low return rates that did not vary among the three Lake Erie basins (Table 3). The WB fish had higher return rates (than those of LSC fish) that did not vary among the three basins. The return rates of $\mathrm{CB}$ fish were lower in $\mathrm{WB}$ than in $\mathrm{CB}$ and $\mathrm{EB}$ $(F=5.2 ; \mathrm{df}=2,30 ; P=0.01)$, and $\mathrm{EB}$ fish had extremely high return rates in $\mathrm{EB}(F=29.7$; df $=2,30$; $P<0.0001)$.

For fish tagged in one basin, length at tagging varied among recapture basins. The LSC males recaptured in WB had a larger mean length at tagging than those recaptured in LSC $(t=-2.93$; df $=13 ; P=0.01)$, but no difference was found for LSC females recaptured in WB and LSC (Figure 2). Length at tagging of WB walleyes varied greatly among recapture basins (males: $F=47.9 ;$ df $=3,2,910 ; P<0.0001$; females: $F=25.8$; df $=3,1,528 ; P<0.0001)$. Both male and female WB walleyes recaptured in LSC were smallest, and the lengths of fish increased progressively from WB to EB. Lengths of WB male (but not female) walleyes recaptured in $\mathrm{CB}$ were smaller than those of male walleyes recaptured in $\mathrm{EB}(t=-2.08$; df $=159 ; P<$ 0.05 ). The $\mathrm{CB}$ females (but not males) recaptured in $\mathrm{CB}$ were larger than those recaptured in $\mathrm{EB}(t=3.29$; df $=70 ; P<0.01)$. Lengths of EB fish of both sexes did not differ between recapture basins $\mathrm{CB}$ and $\mathrm{EB}$. Lengths of fish of both sexes tagged in WB and caught in other basins were generally smaller than or not different from those of fish residing in those basins. For example, lengths of WB fish recaptured in LSC were not different from those of LSC fish caught in LSC. The WB fish of both sexes recaptured in CB and EB, respectively, were smaller than those of fish tagged and recaptured in $\mathrm{CB}$ and $\mathrm{EB}$, respectively (male $\mathrm{WB}$ versus $\mathrm{CB}: t=-6.46$; $\mathrm{df}=88 ; P<0.0001$; male WB versus EB: $t=-5.41$; df $=127 ; P<0.0001$; female WB versus $\mathrm{CB}: t=-3.17$; df $=69 ; P<0.01$; female WB versus $\mathrm{EB}: t=-7.79$; df $=386 ; P<0.0001)$.

\section{Movement Patterns of Major Spawning Stocks in Lake Erie and LSC Basins}

Spatial and temporal patterns in movement, as indexed by tag return data, varied greatly among 
TABLE 3.- Annual standardized tag return rate (number of tags returned per 1,000 tags released) and percentage of annual standardized tag return rate from the walleye sport fishery in Lake St. Clair (LSC) and in the western (WB), central (CB), and eastern (EB) basins of Lake Erie during 1990-2000.

\begin{tabular}{|c|c|c|c|c|c|c|c|c|c|c|c|c|}
\hline \multirow{2}{*}{$\begin{array}{c}\text { Recreational } \\
\text { basin }\end{array}$} & \multirow{2}{*}{$\begin{array}{l}\text { Tagging } \\
\text { basin }\end{array}$} & \multicolumn{11}{|c|}{ Number returned/1,000 released } \\
\hline & & 1990 & 1991 & 1992 & 1993 & 1994 & 1995 & 1996 & 1997 & 1998 & 1999 & 2000 \\
\hline \multicolumn{13}{|c|}{ Tag return rate } \\
\hline \multirow[t]{4}{*}{ WB } & LSC & 3.6 & 0.5 & 0.2 & 0.9 & 0.2 & 0.2 & 0.4 & 0 & 0 & 0 & 0.2 \\
\hline & WB & 6.9 & 9.1 & 8.3 & 8.8 & 4.1 & 3.1 & 2.4 & 2.6 & 1.6 & 0.8 & 1.1 \\
\hline & $\mathrm{CB}$ & 0 & 5.3 & 1.7 & 0.5 & 0.9 & 0.4 & 0 & 0 & 0 & 0 & 0 \\
\hline & $\mathrm{EB}$ & 0 & 0 & 0.2 & 0.2 & 0 & 0 & 0 & 0.2 & 0 & 0 & 0 \\
\hline \multirow[t]{4}{*}{ CB } & LSC & 0.7 & 0 & 0 & 2.7 & 0 & 0 & 0 & 0 & 0 & 0 & 0 \\
\hline & WB & 7.8 & 4.0 & 5.7 & 5.0 & 4.0 & 4.1 & 3.7 & 2.1 & 2.2 & 0.8 & 1.2 \\
\hline & $\mathrm{CB}$ & 26.5 & 54.0 & 28.5 & 14.9 & 14.6 & 15.6 & 10.4 & 3.3 & 3.0 & 0 & 5.3 \\
\hline & $\mathrm{EB}$ & 2.1 & 0 & 0 & 1.3 & 0.2 & 0.5 & 1.0 & 0 & 0.9 & 0.2 & 0.4 \\
\hline \multirow[t]{4}{*}{ EB } & LSC & 0 & 1.7 & 0 & 2.9 & 1.4 & 0 & 0 & 0 & 0 & 0 & 0 \\
\hline & WB & 17.9 & 4.3 & 3.2 & 6.9 & 4.7 & 3.3 & 3.4 & 1.4 & 1.2 & 0.6 & 1.4 \\
\hline & $\mathrm{CB}$ & 72.9 & 29.0 & 18.1 & 24.8 & 35.8 & 24.2 & 9.6 & 4.5 & 4.0 & 0 & 4.9 \\
\hline & EB & 171.1 & 91.5 & 64.7 & 101.4 & 152.5 & 90.9 & 74.7 & 38.8 & 31.5 & 27.8 & 33.8 \\
\hline \multicolumn{13}{|c|}{ Percentage of tag return rate } \\
\hline \multirow[t]{4}{*}{ WB } & LSC & 35 & 3 & 2 & 8 & 4 & 5 & 14 & 0 & 0 & 0 & 15 \\
\hline & WB & 65 & 61 & 79 & 86 & 79 & 84 & 86 & 94 & 100 & 100 & 85 \\
\hline & $\mathrm{CB}$ & 0 & 36 & 17 & 5 & 17 & 11 & 0 & 0 & 0 & 0 & 0 \\
\hline & EB & 0 & 0 & 2 & 1 & 0 & 0 & 0 & 6 & 0 & 0 & 0 \\
\hline \multirow[t]{4}{*}{$\mathrm{CB}$} & LSC & 2 & 0 & 0 & 11 & 0 & 0 & 0 & 0 & 0 & 0 & 0 \\
\hline & WB & 21 & 7 & 17 & 21 & 21 & 20 & 24 & 39 & 36 & 80 & 17 \\
\hline & $\mathrm{CB}$ & 71 & 93 & 83 & 62 & 77 & 77 & 69 & 61 & 49 & 0 & 77 \\
\hline & EB & 6 & 0 & 0 & 6 & 1 & 3 & 7 & 0 & 15 & 20 & 6 \\
\hline \multirow[t]{4}{*}{$\mathrm{EB}$} & LSC & 0 & 1 & 0 & 2 & 1 & 0 & 0 & 0 & 0 & 0 & 0 \\
\hline & WB & 7 & 3 & 4 & 5 & 2 & 3 & 4 & 3 & 3 & 2 & 3 \\
\hline & $\mathrm{CB}$ & 28 & 23 & 21 & 18 & 18 & 20 & 11 & 10 & 11 & 0 & 12 \\
\hline & $\mathrm{EB}$ & 65 & 72 & 75 & 75 & 78 & 77 & 85 & 87 & 86 & 98 & 84 \\
\hline
\end{tabular}

walleye major spawning stocks. During each month, female fish generally had wider ranges of movement than did males of the same stock, but both sexes within a stock had similar directions of movement (Figure 3 ). The LSC stocks 1 and 62 primarily moved northward into LSC, St. Clair River, Saginaw Bay, or southern Lake Huron during May-September. Of the six major WB stocks, stocks 14,40 , and 41 primarily $(>50 \%)$ moved eastward into Lake Erie during May-August. Recaptures of male fish from stock 40 decreased in EB while increasing in WB during September, whereas recaptures of the other two stocks did not show signs of westward movement patterns. The WB stocks 43 and 61 moved northward (in May) before moving eastward (in July), whereas directions of movement by stock 45 were not seasonally distinct. The CB stock 46 primarily moved around $\mathrm{CB}$ in May and June and moved toward EB in July-September. The two EB stocks had the narrowest range of movement among all stocks. Stock 51 fish mostly moved around EB and only dispersed to $\mathrm{CB}$ in July. Stock 53 fish dispersed to $\mathrm{CB}$ and $\mathrm{EB}$ during June-August and only were recaptured in EB in September.

During April (the spawning time of most walleye stocks in Lake Erie), tag returns occurred usually near spawning sites with some exceptions. A number of fish were recaptured away from spawning sites, which probably indicated pre- or postspawning movement by mature fish near spawning time or movement by nonspawning fish. A few male fish of LSC stock 62 were recaptured at site 1 (in LSC), and some fish (male or female) of WB stocks 14, 40, 41, 45, and 61 and CB stock 46 were recaptured near site 43 (Maumee River in WB). Some female fish from stock 53 were caught near site 88 (Walnut Creek in CB) during April. These recaptures suggested that stocks are likely to mix within LSC, between $\mathrm{WB}$ and $\mathrm{CB}$, and between $\mathrm{CB}$ and EB.

The minimum distances moved per recapture month were larger for female fish and generally increased from April to September. Of all stocks combined, minimum distances moved by male fish increased from 19.8 to $84.8 \mathrm{~km}$ and those by female fish increased from 40.9 to $156.1 \mathrm{~km}$ during April-August. Among stocks, minimum distances moved were generally larger for the WB stocks and shorter for the EB stocks (Table 4). A linear regression model was fitted with minimum distances moved per recapture month as the response and sex, length at tagging, and the sex $\times$ length at tagging interaction as predictors. The minimum distances moved appeared to be influenced by sex (female walleyes moved $25.8 \pm 5.0$ [April] to 
A

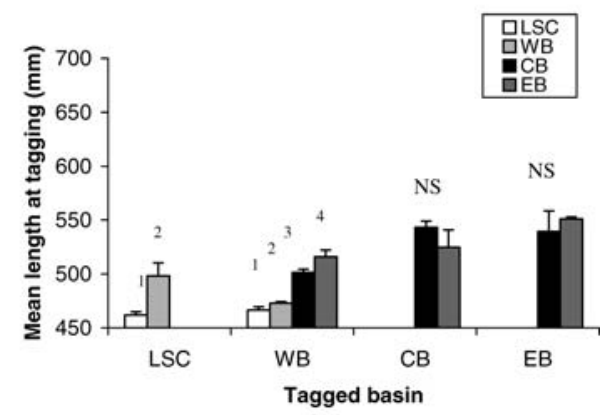

B

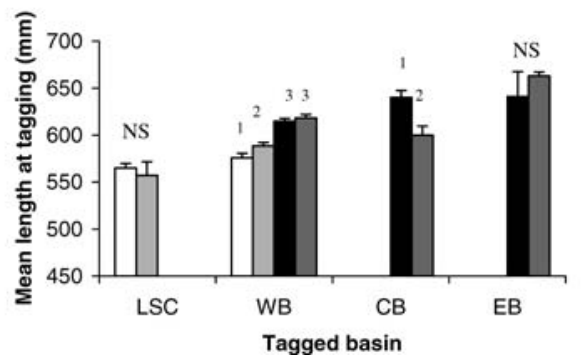

FIGURE 2.- Mean length at tagging $(\mathrm{mm} ;+\mathrm{SE})$ of $(\mathbf{A})$ male and (B) female walleyes by tagging basins ( $x$-axes) and recapture basins (bars) in Lake St. Clair (LSC) and Lake Erie (western [WB], central [CB], and eastern [EB] basins), 19902001. Fish recaptured in the Detroit River, St. Clair River, and southern Lake Huron were classified as LSC recaptures. Numbers above bars represent significant differences (see Results; $P<0.05$ ); NS $=$ no significant difference.

$83.1 \pm 16.0 \mathrm{~km}$ [September] farther than males; $P<$ 0.0001 ) for all stocks. Minimum distances moved by the WB stocks depended on both sex (females moved $29.2 \pm 5.7$ [April] to $33.5 \pm 8.0 \mathrm{~km}$ [July] farther than males; $P<0.05$ ) and length at tagging (walleyes moved $0.12 \pm 0.02$ [May] to $0.47 \pm 0.12 \mathrm{~km}$ [September] farther for each 1-mm increase in length at tagging; $P<0.0001$ ).

Mean lengths at tagging of EB walleye stocks of both sexes were largest (Table 4). Variation in lengths at tagging between sexes was high among the WB stocks.

Temporal and Seasonal Patterns of Walleye Sportfishing and Commercial Fishing Effort and CPUE

Both effort and CPUE of walleye sportfishing in Lake Erie were highest in the WB from April to July (Figure 4). The CPUE in CB then exceeded that in WB during August and September, when sportfishing effort was not different between the WB and CB. Temporal trends in effort and CPUE in EB were similar to those in $\mathrm{CB}$ and were generally lowest among the three basins.

Commercial gill-net effort and CPUE data showed a larger temporal coverage than sportfishing data (Figure 5). From January to March, commercial fishing effort was generally higher in the WB than in the $\mathrm{CB}$, but CPUE did not follow the temporal distribution of fishing effort in the two basins. Highest commercial fishing effort occurred in the WB from April to June, then in the CB from July to August, and then shifted back to WB again from September to December. Temporal trends in commercial CPUE were similar to effort trends from April to December. The CPUE was highest in WB during spring (April-June) and fall to early winter (October-December) but was higher in CB and EB than in WB from July to September. In comparison with sport fisheries data, commercial effort and CPUE in WB peaked from April to June, but sportfishing effort and CPUE were highest from April to July (Figures 4, 5). Both commercial (but not sport) fishing effort and CPUE in WB increased from September to October.

\section{Discussion}

Variation in walleye movement and stock parameters was considerable among basins, spawning stocks, and between sexes. Among Lake Erie walleye stocks, WB stocks displayed the highest degree of movement and were recaptured in $\mathrm{CB}, \mathrm{EB}$, and LSC during spring and summer. The mean lengths at tagging of WB fish recaptured in $\mathrm{CB}$ and $\mathrm{EB}$ were larger than those of $\mathrm{WB}$ fish recaptured in WB and LSC, which implies that the eastward-moving WB fish were generally older or larger in length at age. Such variation in walleye movement behavior and age (or size) may be a sizedependent response to the shallower and warmer surroundings in the WB and LSC (mean depth $=3$ $\mathrm{m})$ relative to $\mathrm{CB}$ and $\mathrm{EB}$ in summer. The average summer temperature in the WB $\left(24^{\circ} \mathrm{C}\right)$ is higher than optimal temperatures for growth of large walleyes (20$23^{\circ} \mathrm{C}$; Coutant 1977 ) and may impose high metabolic costs.

Movement of WB walleyes also may be a response to spatial patterns in prey abundance. In western Lake Erie, walleye diets shift according to the availability of prey fish (Parsons 1971; Knight et al. 1984), and adult walleyes prefer to feed on soft-rayed fish (rainbow smelt Osmerus mordax, spottail shiner Notropis hudsonius, emerald shiner N. atherinoides, silver chub Macrhybopsis storeriana) and clupeids (gizzard shad Dorosoma cepedianum, alewife Alosa pseudoharengus) rather than on spiny-rayed fish (yellow perch Perca flavescens, white perch Morone americana, white bass M. chrysops; Knight and Vondracek 1993). 
A
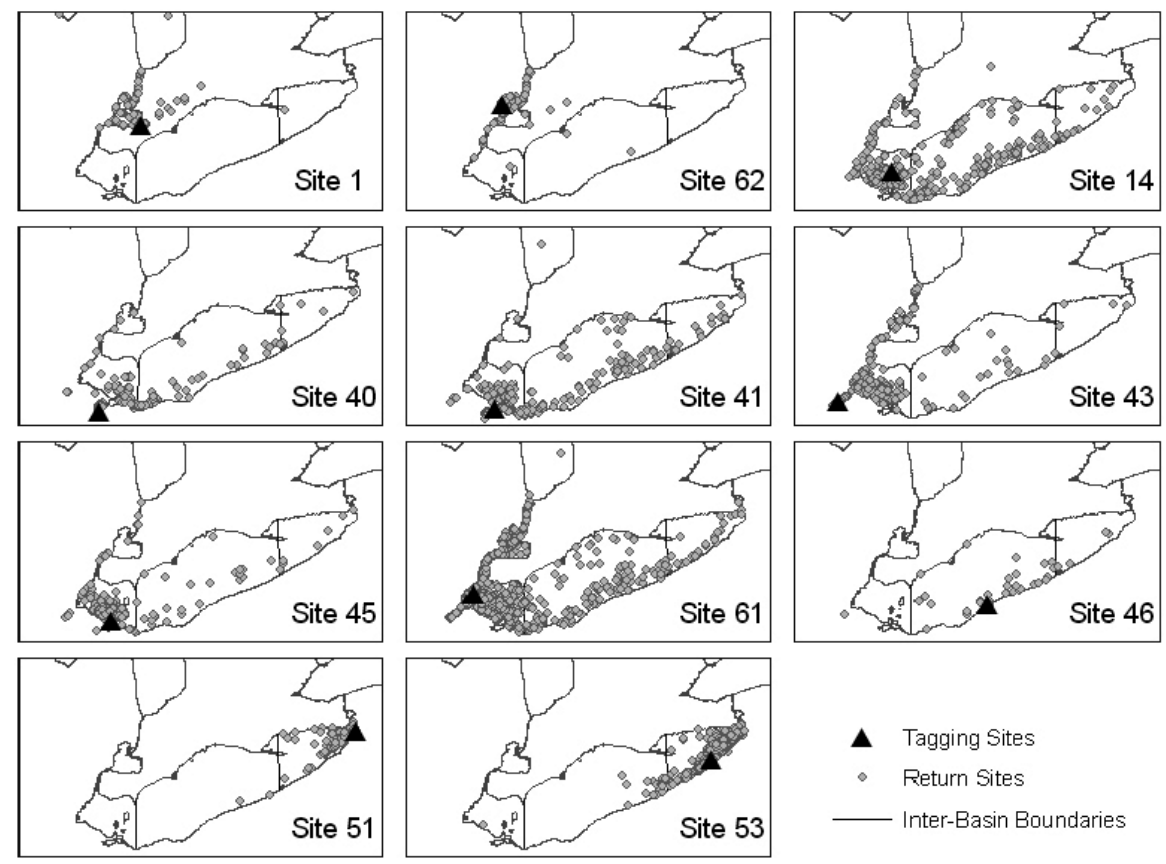

A Tagging Sites

- Return Sites

- Inter-Basin Boundaries

FIGURE 3.-Locations of sportfishing returns of tagged (A) male and (B) female walleyes by major spawning stock in Lake St. Clair (LSC) and Lake Erie, 1990-2001. The stocks were defined based on tagging sites in LSC (sites 1 and 62) and the western (WB; sites 14, 40, 41, 43, 45, and 61), central (CB; site 46), and eastern (EB; sites 51 and 53) basins of Lake Erie.

Clupeids and spiny-rayed fish are fast-growing forage fish that become invulnerable to walleye predation after one growing season, whereas smaller soft-rayed fish of all ages are easily caught and digested by walleyes. Lakewide bottom trawl survey data of forage fish density (Lake Erie Forage Task Group, unpublished data) indicate that soft-rayed fish prefer cooler temperatures. As a result, large WB walleyes may be attracted to soft-rayed fish in the $\mathrm{CB}$ and $\mathrm{EB}$ in summer.

Because the sex ratios of tagged fish were biased toward males (in variable degrees at different tagging sites), the sex ratios of these stocks cannot be compared. However, we observed that female walleyes generally had larger ranges of movement than males recaptured in the same month. In summer, walleyes recaptured by sport anglers in EB were $90 \%$ females (Einhouse and Haas 1995), presumably coming from WB and CB. The observed difference in sex ratios between tagged fish and sport catches in EB may result from the different migratory behaviors between sexes. As female walleyes are usually larger than males at the same age, they incur higher metabolic costs at warm temperatures and, thus, are more likely to migrate than males. Moreover, life history theory predicts that females may increase fecundity by migrating eastward to increase consumption.

Our results suggest that WB walleye stocks that migrate are likely to have larger stock biomass and better reproductive fitness than nonmigrating WB stocks, as fecundity is positively correlated with fish size (Muth and Ickes 1993; Henderson and Nepszy 1994). Also, the WB stocks that migrate may have higher growth rates than the nonmigrating WB stocks by reducing metabolic cost incurred by warm water. The second hypothesis is supported by a previous modeling study examining consumption and growth rates among two resident walleye populations in the WB and CB and one migratory population between basins (Kershner et al. 1999). The authors showed that the migratory population maximizes growth rates by accessing optimal temperatures in either basin.

The walleye spawning stocks varied in mean length at tagging, movement path, and minimum distances moved per recapture month. The variable patterns of migratory behaviors suggest that some of these walleye stocks are more closely related than others. Todd and Haas (1993) evaluated stock uniqueness of walleyes in Lake Erie and LSC from tag returns between 1978 and 1987 and genetic data. They found that variation in 
B
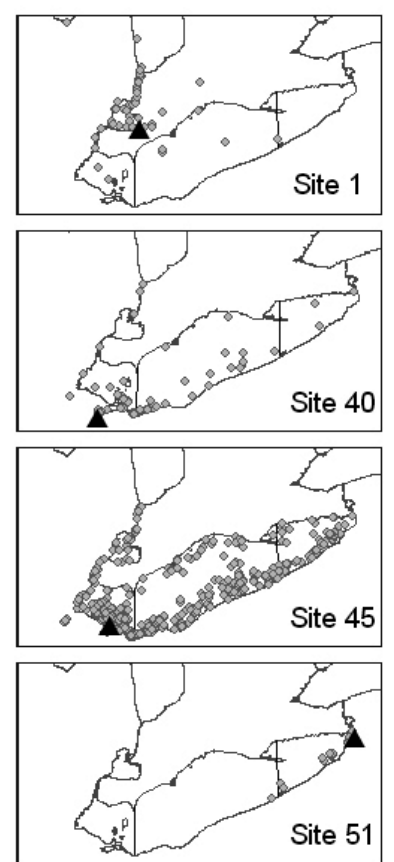
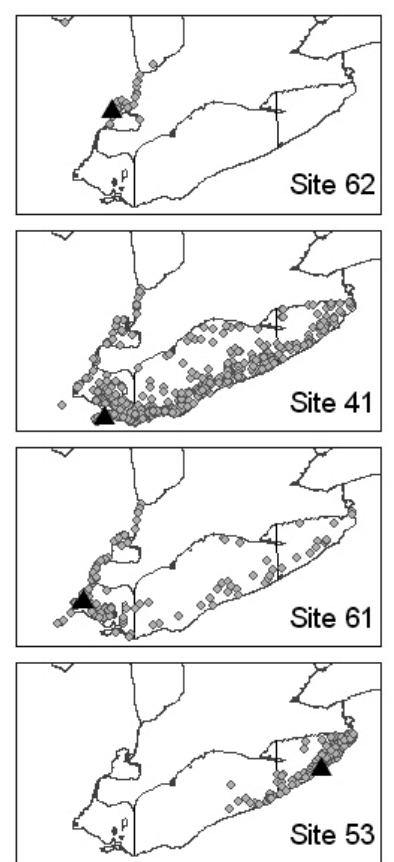
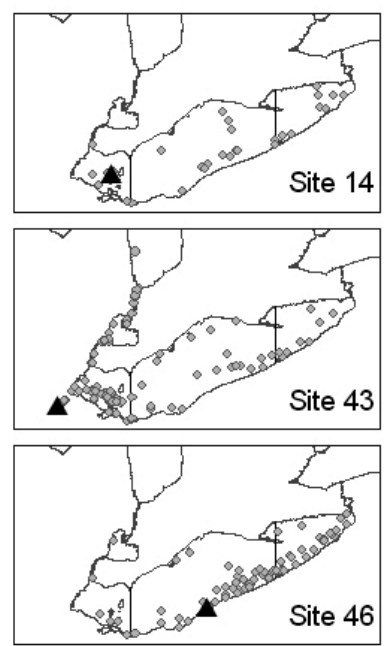

- Tagging Sites

- Return Sites

Inter-Basin Boundaries

Figure 3.-Continued.

allele frequencies was pronounced among stocks between the two lakes (but not within either lake), despite tag return data, suggesting the two lake populations intermingled when walleyes migrated northward from Lake Erie into LSC during spawning and nonspawning seasons. Examination of the recent tag return data (1990-2001) in LSC, Lake Huron, and all of the tributaries north of Lake Erie originally grouped into LSC provided further support for the conclusions made by Todd and Haas (1993). Our analyses indicated that several walleyes of stocks 60 , 62, and 63 migrated north to St. Clair River during spring and summer months (April-August), while only a few fish from stocks 62 and 63 migrated into Lake Erie. Consequently, our results and those of Todd and Haas (1993) suggest that LSC and WB walleye stocks intermingle during the spawning runs, but the variation in mean length at tagging and migratory behaviors among WB stocks found in our study were not reflected in the genetic variation reported by Todd

TABLE 4.-Mean ( \pm SE) minimum distance moved and length at tagging of male $(\mathrm{M})$ and female $(\mathrm{F})$ walleyes of different stocks in Lake St. Clair (LSC) and the western (WB), central (CB), and eastern (EB) basins of Lake Erie. Mean minimum distance moved was calculated as the average distance between the tagging site and recapture location during April to September, 1990-2001.

\begin{tabular}{|c|c|c|c|c|c|c|}
\hline \multirow{2}{*}{$\begin{array}{c}\text { Tagging } \\
\text { basin }\end{array}$} & \multirow[b]{2}{*}{ Tagging site } & \multirow[b]{2}{*}{$\mathrm{N}(\mathrm{M}+\mathrm{F})$} & \multicolumn{2}{|c|}{ Mean minimum distance moved $(\mathrm{km})$} & \multicolumn{2}{|c|}{ Mean length at tagging $(\mathrm{mm})$} \\
\hline & & & M & $\mathrm{F}$ & M & $\mathrm{F}$ \\
\hline \multirow[t]{2}{*}{ LSC } & 1 & 139 & $53.3 \pm 5.4$ & $80.1 \pm 7.9$ & $465 \pm 6.2$ & $575 \pm 5.6$ \\
\hline & 62 & 190 & $34.4 \pm 3.4$ & $34.4 \pm 6.3$ & $463 \pm 3.5$ & $551 \pm 6.6$ \\
\hline \multirow[t]{6}{*}{ WB } & 14 & 407 & $67.8 \pm 3.6$ & $164.7 \pm 17.8$ & $471 \pm 2.3$ & $580 \pm 10.5$ \\
\hline & 40 & 196 & $58.9 \pm 6.3$ & $88.9 \pm 11.7$ & $468 \pm 3.9$ & $614 \pm 7.6$ \\
\hline & 41 & 774 & $94.0 \pm 5.9$ & $137.2 \pm 4.4$ & $511 \pm 3.1$ & $621 \pm 2.6$ \\
\hline & 43 & 438 & $58.2 \pm 3.6$ & $140.6 \pm 10.0$ & $486 \pm 2.9$ & $603 \pm 6.4$ \\
\hline & 45 & 614 & $50.7 \pm 4.8$ & $118.8 \pm 4.7$ & $473 \pm 4.6$ & $593 \pm 3.9$ \\
\hline & 61 & 1,520 & $56.3 \pm 1.7$ & $100.3 \pm 8.2$ & $475 \pm 1.8$ & $562 \pm 6.2$ \\
\hline $\mathrm{CB}$ & 46 & 136 & $46.0 \pm 7.3$ & $88.7 \pm 7.4$ & $541 \pm 5.7$ & $625 \pm 6.1$ \\
\hline \multirow[t]{3}{*}{$\mathrm{EB}$} & 51 & 243 & $19.4 \pm 1.7$ & $49.5 \pm 10.2$ & $547 \pm 3.4$ & $676 \pm 13.1$ \\
\hline & 53 & 696 & $27.5 \pm 1.0$ & $38.1 \pm 2.1$ & $550 \pm 2.4$ & $661 \pm 4.5$ \\
\hline & All sites & 5,353 & $52.5 \pm 1.0$ & $110.4 \pm 2.4$ & $493 \pm 1.1$ & $607 \pm 1.7$ \\
\hline
\end{tabular}




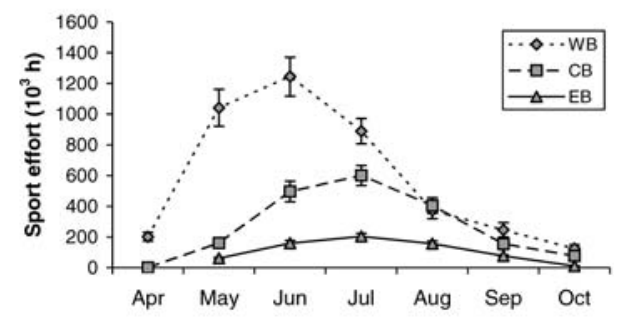

B

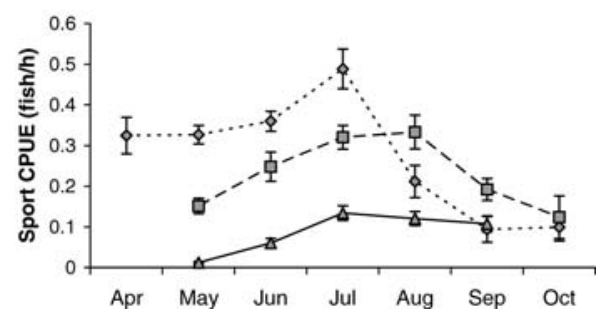

FigurE 4.-Mean ( \pm SE) monthly walleye (A) sportfishing effort (h) and (B) CPUE (fish/h) during April-October in the three basins (western [WB], central [CB], and eastern [EB]) of Lake Erie, 1990-2001 (data are from creel survey data collected in Michigan, Ohio, Pennsylvania, and New York waters).

and Haas (1993). This discrepancy suggests that the variable movement patterns and size among WB stocks reflect behavioral or phenotypic variation.

Our findings that walleye spawning stocks show distinct movement patterns may have been potentially compromised by sampling bias, angler returns, tagging effect and tag loss, or variable nonreporting rates. For example, length at tagging of fish could be biased from different sampling gear used. Using data on tag returns by anglers may result in bias because of different fishing schedules in the three basins, nonrandom fishing locations, and variation in fishing behavior among individuals. The fishing season in the WB is usually one month earlier than in the $\mathrm{CB}$ and $\mathrm{EB}$, which limits the possibility of observing early movement of WB fish. Also, walleye movement inferred based on tag return data could potentially be confounded by the spatial and temporal changes in sportfishing effort. We were aware that tagging might alter fish movement behaviors and survival rates to certain degrees (Olney et al. 2006), but without data support we had to assume that the effect of tagging did not vary among basins. Similarly, tag loss could have affected our estimates of tag return rates if rates of tag loss varied across basins or among stocks. All walleye tagging involved use of a monel metal tag placed in the

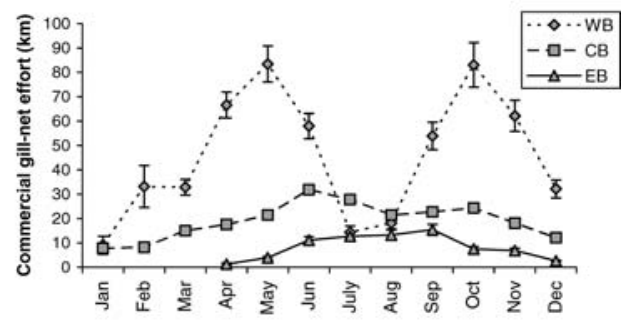

B

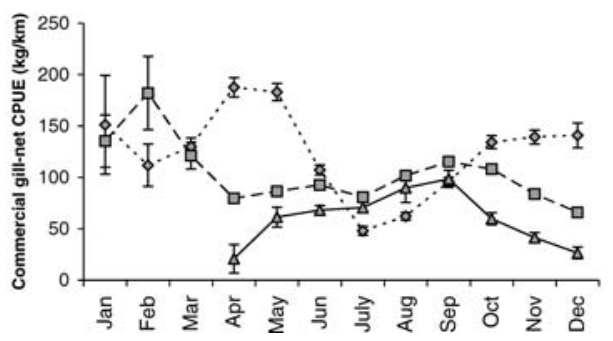

FigurE 5.-Mean ( \pm SE) monthly walleye (A) commercial gill-net fishing effort (length [km] of gill-net effort) and (B) CPUE ( $\mathrm{kg}$ of fish $/ \mathrm{km}$ ) during January-December in the three basins (western [WB], central [CB], and eastern [EB]) of Lake Erie, 1990-2001 (data from northern waters, estimated by the Ontario Ministry of Natural Resources).

lower jaw and was performed by experienced resource agency personnel, although slightly different tagging procedures were followed. We believe that effect of tag loss was minimized in the design of the tagging program, but without any estimates we could not conclude significance of the effect. Little information existed on nonreporting bias by sport anglers, which may have confounded our interpretation of tag return data. Thomas and Haas (2001) showed that ratios of nonreporting to reporting by sport fishermen were similar in 1990 and 2000, yet their results did not readily suggest a constant nonreporting rate over years. Therefore, we do not have reasonable estimates of nonreporting rates and it was necessary to assume a constant nonreporting rate for all study years examined. Moreover, the majority of the lakewide harvest of walleyes has shifted more to commercial fishing, which has a higher nonreporting rate of tags. We believe that nonreporting by commercial fishermen will not affect our conclusions if the sport fishery is representative of the overall population.

Our estimates of minimum distances moved and movement path for each spawning population may also be biased by assuming that fish moved directly from 
tagging sites to recapture locations, but our inference of seasonal (monthly) changes in walleye distribution should be less biased from making this assumption. Future research should use implanted transmitters to provide direct observations of walleye movement. Finally, estimates of minimum distances moved may be biased because of high fishing intensity near spawning grounds in spring.

Integration of the patterns of walleye tag returns and spatial and temporal trends of fisheries effort and CPUE suggests that the migratory WB stocks may have supported sport and commercial harvest in the $\mathrm{CB}$ and EB of Lake Erie and even outside Lake Erie. Tag returns provide direct evidence of walleye migration from Lake Erie to Detroit River, LSC, St. Clair River, and southern Lake Huron, and migration within Lake Erie. The migratory patterns of walleyes were consistently and repeatedly observed during the 12 study years. Although we only examined the tags returned by anglers primarily from southern Lake Erie, the similar spatial and temporal patterns of commercial and sportfishing effort and catch data suggest that seasonal distributions of walleyes in northern Lake Erie were similar to those in southern Lake Erie and that our tagging results from southern Lake Erie may be relevant for the whole lake. In addition to our results from tag returns, sport harvest data in southern Lake Erie, and commercial harvest data in northern Lake Erie, a previous study (Henderson and Wong 1994) provided similar annual migratory patterns of walleyes with the use of commercial gill-net catch data from 1985 to 1992 in the Ontario waters of Lake Erie (northern Lake Erie). Their data on commercial catch rates during the earlier time period were consistent with the patterns we observed from commercial CPUE data from 1990 to 2001 .

Our findings are supported by several prior studies of Lake Erie walleye migratory behavior, growth, and habitat use. Kershner et al. (1999) suggested a densityindependent factor (temperature) regulates walleye migration between $\mathrm{WB}$ and $\mathrm{CB}$, and that migratory fish have higher growth rates. As the major eastward dispersal of WB walleye stocks (indicated by WB tag returns in the $\mathrm{CB}$ and $\mathrm{EB}$ ) generally occurs in July, the eastward movement did appear to be a response to warm temperatures. However, our analyses of tag return data indicate that some WB walleye stocks migrate to $\mathrm{CB}$ or $\mathrm{EB}$ before July, when temperatures in WB are still below the stressful levels of $24^{\circ} \mathrm{C}$ and higher. A literature review by Colby et al. (1979) indicates that preferred size of forage fishes is positively correlated with size of walleyes. The eastward migratory behavior of large WB walleyes may have been in response to migrating stocks of large forage fishes to the east. With more complete information on walleye forage fish movements, this hypothesis about the stimulus for Lake Erie walleye migration may be tested. Another observation from Colby et al. (1979) indicated that adult walleyes move into deeper waters in late summer to early fall (either from tributaries to lakes or from inshore to offshore areas) because of rising water temperature, movements of prey fishes, adaptation to different degrees of light attenuation, or a combination thereof. Walleyes are not commonly encountered below the thermocline owing to low oxygen concentrations in $\mathrm{CB}$ or low temperatures in EB, but are observed to feed on rainbow smelt around the thermocline in EB (D.W.E., unpublished data). Winter movements of walleyes also are confined by water temperature, as the fish move deeper or stay near shore according to temperature patterns (Colby et al. 1979).

The findings from our study are critical for resource agencies to evaluate the dynamics of walleye harvest during the last decade. To properly manage walleye fisheries in Lake Erie, it is important to understand the variable movement behaviors and life histories of different walleye stocks and link those to the spatial and temporal trends of walleye harvests. Finally, our results may serve as a basis for future analyses and design of a sustainable walleye harvest protocol.

We conclude that there is substantial variation in walleye movement behaviors between sexes, among spawning stocks, and among Lake Erie and LSC basins. The walleyes that moved the greater distances were generally composed of larger (or older) walleyes and higher proportions of females than the fish that moved less. Primary factors that stimulate walleye movement may include density-independent effects, such as water temperature and forage fish density and species types. Further investigations of walleye growth and life history patterns in response to Lake Erie habitats should attempt to distinguish responses among spawning stocks in the three basins.

\section{Acknowledgments}

Funding was provided by the Great Lakes Fisheries Commission. The authors are grateful to all of the field crews for data collection. We also thank Christine Geddes for geographical information systems consultation, Renate Snider for editing, and many university and agency staff for discussions of analytical methods and details of the walleye fishery through the project.

\section{References}

Colby, P. J., R. E. McNicol, and R. A. Ryder. 1979. Synopsis of biological data on the walleye Stizostedion v. vitreum 
(Mitchill 1818). FAO (Food and Agriculture Organization of the United Nations) Fisheries Synopsis 119.

Coutant, C. C. 1977. Compilation of temperature preference data. Journal of the Fisheries Research Board of Canada 34:739-745.

Einhouse, D. W., and R. C. Haas. 1995. A preliminary examination of walleye distribution and exploitation in the eastern basin of Lake Erie using tag-recapture data. New York State Department of Environmental Conservation, Albany.

Ferguson, R. G., and A. J. Derksen. 1971. Migrations of adult and juvenile walleyes (Stizostedion vitreum vitreum) in southern Lake Huron, Lake St. Clair, Lake Erie, and connecting waters. Journal of the Fisheries Research Board of Canada 28:1133-1142.

Fielder, D. G. 2002. Sources of walleye recruitment in Saginaw Bay, Lake Huron. North American Journal of Fisheries Management 22:1032-1040.

Fitzsimons, J. D., J. H. Leach, S. J. Nepszy, and V. W. Cairns. 1995. Impacts of zebra mussel on walleye (Stizostedion vitreum) reproduction in western Lake Erie. Canadian Journal of Fisheries and Aquatic Sciences 52:578-586.

Gatt, M. H., T. L. McParland, L. C. Halyk, and M. M. Ferguson. 2003. Mitochondrial DNA variation and mixed stock analysis of recreational and commercial walleye fisheries in Eastern Lake Erie. North American Journal of Fisheries Management 23:431-440.

Gopalan, G., D. A. Culver, L. Wu, and B. K. Trauben. 1998. Effects of recent ecosystem changes on the recruitment of young-of-the-year fish in western Lake Erie. Canadian Journal of Fisheries and Aquatic Sciences 55:2572-2579.

Haas, R. C., M. C. Fabrizio, and T. N. Todd. 1988. Identification, movement, growth, mortality, and exploitation of walleye stocks in Lake St. Clair and the western basin of Lake Erie. Michigan Department of Natural Resources, Fisheries Research Report 1954, Ann Arbor.

Hartman, K. J., and F. J. Margraf. 1992. Effects of prey and predator abundances on prey consumption and growth of walleyes in western Lake Erie. Transactions of the American Fisheries Society 121:245-260.

Hatch, R. W., S. J. Nepszy, K. M. Muth, and C. T. Baker. 1987. Dynamics of the recovery of the western Lake Erie walleye (Stizostedion vitreum vitreum) stock. Canadian Journal of Fisheries and Aquatic Sciences 44:15-22.

Henderson, B. A., and S. J. Nepszy. 1994. Reproductive tactics of walleye (Stizostedion vitreum) in Lake Erie. Canadian Journal of Fisheries and Aquatic Sciences 51:986-997.

Henderson, B. A., and J. L. Wong. 1994. Migration of walleye in Lake Erie: life history tactic for optimum growth and reproduction. Ontario Ministry of Natural Resources, Aquatic Ecosystem Research Section, Population Ecology Unit, Report to Walleye Task Group of Lake Erie Standing Technical Committee, Maple.

Höök, T. O., E. S. Rutherford, S. J. Brines, C. A. Geddes, D. M. Mason, D. J. Schwab, and G. W. Fleischer. 2004. Landscape scale measures of steelhead (Oncorhynchus mykiss) bioenergetic growth rate potential in Lake Michigan and comparison with angler catch rates. Journal of Great Lakes Research 30(4):545-556.

Kershner, M. W., D. M. Schael, R. L. Knight, R. A. Stein, and E. A. Marschall. 1999. Modeling sources of variation for growth and predatory demand of Lake Erie walleye (Stizostedion vitreum), 1986-1995. Canadian Journal of Fisheries and Aquatic Sciences 56:527-538.

Knight, R. L., F. J. Margraf, and R. F. Carline. 1984. Piscivory by walleye and yellow perch in western Lake Erie. Transactions of the American Fisheries Society 113:677-693.

Knight, R. L., and B. Vondracek. 1993. Changes in prey fish populations in western Lake Erie, 1969-88, as related to walleye, Stizostedion vitreum, predation Canadian Journal of Fisheries and Aquatic Sciences 50:1289-1298.

Koonce, J. F., W.-D. N. Busch, and T. Czapla. 1996. Restoration of Lake Erie: contribution of water quality and natural resource management. Canadian Journal of Fisheries and Aquatic Sciences 53(Supplement S1):105112.

Ludsin, S. A., M. W. Kershner, K. A. Blocksom, R. L. Knight, and R. A. Stein. 2001. Life after death in Lake Erie: nutrient controls drive fish species richness, rehabilitation. Ecological Applications 11:731-746.

Madenjian, C. P., J. T. Tyson, R. L. Knight, M. W. Kershner, and M. L. Hensen. 1996. First-year growth, recruitment, and maturity of walleyes in western Lake Erie. Transactions of the American Fisheries Society 125:821-830.

Makarewicz, J. C., and P. Bertram. 1991. Evidence for the restoration of the Lake Erie ecosystem. BioScience 41:216-223.

McParland, T. L., M. M. Ferguson, and A. P. Liskauskas. 1999. Genetic population structure and mixed-stock analysis of walleyes in the Lake Erie-Lake Huron corridor using allozyme and mitochondrial DNA markers. Transactions of the American Fisheries Society 128:1055-1067.

Mellina, E., S. G. Hinch, K. D. MacKenzie, and G. Pearson. 2005. Seasonal movement patterns of stream-dwelling rainbow trout in North-Central British Columbia, Canada. Transactions of the American Fisheries Society 134:1021-1037.

Merker, R. J., and R. C. Woodruff. 1996. Molecular evidence for divergent breeding groups of walleye (Stizostedion vitreum) in tributaries to Western Lake Erie. Journal of Great Lakes Research 22(2):280-288.

Muth, K. M., and B. S. Ickes. 1993. Fecundity of walleyes in western Lake Erie, 1966 and 1990-91. Journal of Great Lakes Research 19:715-719.

Nepszy, S. J. 1999. The changing fishery regime in Lake Erie. Backhuys, Leiden, The Netherlands.

Ohio Department of Natural Resources. 2001. Ohio's Lake Erie Fisheries 2000. Ohio Department of Natural Resources, Division of Wildlife, Lake Erie Fisheries Units, Fairport and Sandusky.

Olney, J. E., R. J. Latour, B. E. Watkins, and D. G. Clarke. 2006. Migratory behavior of American shad in the York River, Virginia, with implications for estimating in-river exploitation from tag recovery data. Transactions of the American Fisheries Society 135:889-896.

Parsons, J. W. 1971. Selective food preferences of walleyes of the 1959 year class in Lake Erie. Transactions of the American Fisheries Society 3:474-485.

Rasul, N., J. P. Coakley, and R. Pippert. 1999. Sedimentary environment of western Lake Erie: geologic setting, 
sediment distribution and anthropogenic effects. Backhuys, Leiden, The Netherlands.

Schertzer, W. C. 1999. Physical limnological characteristics of Lake Erie and implication of climate changes. Backhuys, Leiden, The Netherlands.

Schwarz, C. J., J. F. Schweigert, and A. N. Arnason. 1993. Estimating migration rates using tag-recovery data. Biometrics 49:177-193.

Stepien, C. A., and J. E. Faber. 1998. Population genetic structure, phylogeography and spawning philopatry in walleye (Stizostedion vitreum) from mitochondrial DNA control region sequences. Molecular Ecology 7:17571769.
Thomas, M. V., and R. C. Haas. 2001. Dynamics of Lake Erie walleye and yellow perch populations and fisheries. Michigan Department of Natural Resources, Federal Aid in Sport Fish Restoration, Performance Report F-81-R-2, Study 460, Ann Arbor.

Todd, T. N., and R. C. Haas. 1993. Genetic and tagging evidence for movement of walleyes between Lake Erie and Lake St. Clair. Journal of Great Lakes Research 19(2):445-452.

Wolfert, D. R. 1963. The movement of walleyes tagged as yearlings in Lake Erie. Transactions of American Fisheries Society 92:414-420. 